\title{
Evaluation of Characteristics of Gastrointestinal Adverse Events with Once-Weekly Dulaglutide Treatment in Chinese Patients with Type 2 Diabetes: A Post Hoc Pooled Analysis of Two Randomized Trials
}

\author{
Lixin Guo · Bin Zhang · Jianing Hou (D) - Zhiguang Zhou
}

Received: April 29, 2020 / Published online: July 4, 2020

(c) The Author(s) 2020

\section{ABSTRACT}

Introduction: Gastrointestinal (GI) events are a common side effect of glucagon-like peptide 1 (GLP-1) receptor agonists (RA) class. This post hoc analysis assessed the characteristics of GI adverse events in Chinese patients with type 2 diabetes (T2D) who were treated with onceweekly dulaglutide from two randomized clinical trials.

Digital Features To view digital features for this article go to https://doi.org/10.6084/m9.figshare.12499958.

L. Guo

Department of Endocrinology, Beijing Hospital, National Center of Gerontology, No.1, Dahua Road, Dongcheng District, Beijing 100730, China

\section{B. Zhang · J. Hou ( $₫)$}

Lilly Suzhou Pharmaceutical Co., Ltd, 19F, Tower 1 HKRI, Taikoo Hui, No. 288, Shi Men No. 1 Rd, Shanghai 200041, China

e-mail: hou_jia_ning@lilly.com

\section{Z. Zhou ( $\square)$}

Department of Metabolism and Endocrinology, The Second Xiangya Hospital, Central South University, 139 Renmin Road, Changsha 410011, Hunan, China

e-mail: zhouzhiguang@csu.edu.cn

\section{Z. Zhou}

Key Laboratory of Diabetes Immunology (Central South University), Ministry of Education, National Clinical Research Center for Metabolic Diseases, Changsha, China
Methods: Chinese patients with $\mathrm{T} 2 \mathrm{D}$, treated with once-weekly dulaglutide $(1.5 \mathrm{mg}$ and $0.75 \mathrm{mg}$ ) from two phase III multicenter trials (AWARD-CHN1 and AWARD-CHN2) were included. Descriptive statistics were used to present the data. The characteristics (incidence, severity, onset, duration, and time of occurrence) of GI adverse events reported through 26 weeks in a Chinese subpopulation from the two trials were investigated.

Results: A total of 787 Chinese patients with T2D were included in this analysis. Up to week 26, 225 patients (28.6\%) reported at least one GI treatment-emergent adverse event (TEAE). The most frequently reported GI TEAEs were diarrhea $(13.1 \%)$, nausea $(6.6 \%)$, abdominal distension (6.4\%), and vomiting (3.0\%), with most being categorized as mild to moderate in severity in proportions of $92 \%, 88 \%, 94 \%$, and $83 \%$, respectively. A total of 12 patients $(1.5 \%)$ discontinued the dulaglutide treatment as a result of GI TEAEs. The median duration of the first reported GI TEAEs was 4.0, 5.0, 12.5, and 4.0 days for diarrhea, nausea, abdominal distension, and vomiting, respectively. The incidence of GI TEAEs was more frequent during the first 2 weeks of dulaglutide treatment; however, the incidence declined rapidly after 2 weeks and remained low until week 26 .

Conclusions: Most of the GI TEAEs associated with once-weekly dulaglutide $(1.5 \mathrm{mg}$ and $0.75 \mathrm{mg}$ ) were mild to moderate in severity. The incidence of GI TEAEs was more pronounced 
during the first 2 weeks of dulaglutide treatment but declined rapidly as treatment continued, and was low at week 26, indicating that dulaglutide was well tolerated in Chinese patients with T2D.

Trial Registration: NCT01648582 and NCT01644500.

Keywords: Chinese patients; Dulaglutide; Gastrointestinal adverse events; Pooled analysis; Post hoc analysis; Type 2 diabetes

\section{Key Summary Points}

\section{Why carry out this study?}

Dulaglutide, a once-weekly glucagon-like peptide 1 (GLP-1) receptor agonist (RA), is a proven treatment option as an adjunct to diet and exercise to improve glycemic control in adults with type 2 diabetes (T2D), but gastrointestinal (GI) adverse events are a common side effect of GLP-1 RAs.

Studies with GLP-1 RAs have reported that GI adverse events occurred more frequently in lower versus higher body mass index (BMI) baseline subgroups. Chinese patients with T2D have lower BMI compared with western patients with T2D.

The detailed incidence of GI events associated with dulaglutide in a Chinese patient population was not previously evaluated; thus, in this analysis we are seeking detailed characteristics of GI events in Chinese patients treated with once-weekly dulaglutide.

The current post hoc pooled analysis of two randomized, phase III trials analyzed the GI data in Chinese patients with T2D who were receiving once-weekly dulaglutide $(1.5 \mathrm{mg}$ or $0.75 \mathrm{mg}$ ) in the AWARD-CHN studies

\section{What was learned from the study?}

Results show that at week 26 primary endpoint, $28.6 \%$ of patients reported at least one GI treatment-emergent adverse event (TEAE) and the most frequently reported GI TEAEs were diarrhea (13.1\%), nausea $(6.6 \%)$, abdominal distension (6.4\%), and vomiting (3.0\%). The majority of these most frequently reported GI TEAEs with once-weekly dulaglutide (1.5 $\mathrm{mg}$ and $0.75 \mathrm{mg}$ ) were mild to moderate in severity, were more pronounced during the first 2 weeks, and incidence declined rapidly as treatment continued to week 26.

The findings of this post hoc analysis of two phase III studies indicate that dulaglutide is well tolerated in Chinese patients with T2D and are comparable with GI TEAEs observed with global and other Asian patient populations.

\section{INTRODUCTION}

According to the International Diabetes Federation (IDF), type 2 diabetes (T2D) affects 451 million people globally [1]. China, which is the most populous country, ranks number one with an estimated 109.6 million adults with diabetes [2]. Currently, there are different options, including both oral and injectable medications, for the treatment of T2D [3]. The recently updated American Diabetes Association (ADA) guidelines recommends that-for patients with T2D who have established atherosclerotic cardiovascular disease or indicators of high risk, established kidney disease, or heart failure-a glucagon-like peptide 1 (GLP-1) receptor agonist (RA) or sodium-glucose cotransporter 2 (SGLT2) inhibitor with demonstrated cardiovascular disease benefit be prescribed as part of the glucoselowering regimen independent of glycated hemoglobin A1c (HbA1c) and in consideration of patient-specific factors. Also, in patients who 
need greater glucose-lowering, oral agents and GLP-1 RAs are preferred to insulin when possible $[4,5]$. According to the Chinese Diabetes Society (CDS) guidelines, GLP-1 RAs can effectively lower blood glucose, significantly reduce body weight, and in addition improve triglycerides and blood pressure. Previous studies have shown that the addition of GLP-1 RAs is effective in lowering blood glucose in patients with T2D who have inadequate glycemic control with oral antihyperglycemic medications (OAMs). Furthermore, in patients with T2D and cardiovascular risk, GLP-1RAs have been shown to exert protective effects [6].

Recently, treatment strategies have changed to balance glycemic and non-glycemic outcomes and to prevent or slow the progressive decline in beta cell function in patients with T2D [7]. GLP-1 RAs regulate blood glucose by activating the GLP-1 RA receptors, enhancing insulin secretion, and inhibiting glucagon secretion in a glucose-dependent manner. These agents delay gastric emptying and thus reduce food intake via central appetite suppression, although this differs between GLP-1 RAs depending on long- and short-acting and other specific properties based on molecular structure. Along with GLP-1 RA signaling (i.e., suppression of glucagon secretion, slowed gastric emptying, and increased satiety), GLP-RAs also help in the secretion of cell-mediated insulin [8].

Dulaglutide, a once-weekly GLP-1 RA, was evaluated in the Assessment of Weekly AdministRation of LY2189265 in Diabetes (AWARD) trials mainly in Caucasian patients with T2D and was proven to be efficacious and tolerable as both monotherapy and add-on therapy. In the AWARD studies, dulaglutide demonstrated significant improvements in glycemic control irrespective of gender, duration of diabetes ( $<5$ years, $\geq 5$ to $<10$ years, $\geq 10$ years), or baseline HbA1c $(<8.5 \%, \geq 8.5 \%)$, with greater HbA1c and fasting blood glucose (FBG) reductions in patients having a higher baseline HbA1c. Furthermore, when compared with active comparators (e.g., metformin, sitagliptin, exenatide twice daily, or insulin glargine), dulaglutide showed lower risk of weight gain or hypoglycemia [9-19]. In Chinese patients with T2D, dulaglutide showed similar efficacy, safety, and tolerability as reported in the subgroup analysis of the AWARD trials [20, 21]. Dulaglutide received approval in the USA and European Union (EU) in September 2014 for treatment in adult patients with T2D as an adjunct to diet and exercise and was subsequently launched in April 2019 in the Chinese market.

Evidence showed that dulaglutide was effective in a global and Asian patient population with few incidences of gastrointestinal (GI) treatment-emergent adverse events (TEAEs) [9-21], consistent with GI TEAEs reported in other GLP-1 RAs [22]. Previous studies with GLP-1 RAs have reported that GI adverse events occurred more frequently in lower versus higher body mass index (BMI) baseline subgroups [23], and Chinese patients with T2D have lower BMI compared with western patients [2]. However, the detailed incidence of GI events associated with dulaglutide in a Chinese patient population has not been previously evaluated.

In the current post hoc pooled analysis of two randomized, phase III trials [20, 21], we assessed the characteristics of GI adverse events in subgroups of Chinese patients with T2D who received once-weekly dulaglutide $(1.5 \mathrm{mg}$ or $0.75 \mathrm{mg})$.

\section{METHODS}

\section{Study Design and Treatment}

The present analysis included patient data from two randomized, phase III clinical trials [AWARD-CHN1 (NCT01644500) and AWARDCHN2 (NCT01648582)] of 26- and 52-week duration, respectively. Individual trial results were previously published $[20,21]$. The primary endpoint of both studies assessed the change in HbA1c from baseline at week 26. Both studies enrolled Chinese adult patients with T2D who were randomly assigned to dulaglutide $(1.5 \mathrm{mg}$ and $0.75 \mathrm{mg}$ ) or active comparator. The studies evaluated the efficacy and safety of once-weekly dulaglutide (1.5 $\mathrm{mg}$ and $0.75 \mathrm{mg}$ ) versus an active comparator (glimepiride in AWARDCHN1 and glargine in AWARD-CHN2). 


\section{Patients}

All Chinese patients treated with once-weekly dulaglutide (1.5 $\mathrm{mg}$ and $0.75 \mathrm{mg}$ ), and meeting the previously described inclusion and exclusion criteria in AWARD-CHN1 and AWARDCHN2, were included in the post hoc analyses.

The key inclusion criteria in AWARD-CHN1 included patients with $\mathrm{BMI} \geq 19$ and $\leq 35 \mathrm{~kg} /$ $\mathrm{m}^{2}$ who were OAM-naïve (with $\mathrm{HbA1c} \geq 7.0 \%$ and $\leq 10.5 \%$ at screening) or were taking OAM monotherapy at least 3 months before screening (with $\mathrm{HbA} 1 \mathrm{c} \geq 6.5 \%$ and $\leq 10.0 \%$ at screening). The major inclusion criteria in AWARD-CHN2 study included men or nonpregnant, non-breastfeeding women aged at least 18 years with a diagnosis of T2D for at least 6 months before the screening visit based on the World Health Organization (WHO)'s diagnostic and classification criteria, with a BMI $\geq 19.0$ and $\leq 35.0 \mathrm{~kg} / \mathrm{m}^{2}$, and qualifying HbA1c values of $\geq 7.0 \%$ to $\leq 11.0 \%[20,21]$. In addition, patients who were on metformin and/or a sulfonylurea for at least 3 months before screening and were stable on therapeutic dose [at least half of the maximum dose according to the product information in the participating countries (China, South Korea, and Taiwan in AWARD-CHN1, and China, South Korea, Mexico, and Russia in AWARD-CHN2) of treatment] were included.

Institutional ethics committee approval was obtained for both studies, and written informed consent was taken from each patient before participation. Both studies were conducted in accordance with the Declaration of Helsinki, Good Clinical Practice, and applicable laws and regulations (World Medical Association Declaration of Helsinki, 1997) [24].

\section{Study Assessments and Statistical Analyses}

In the present post hoc analysis, the GI safety of dulaglutide $1.5 \mathrm{mg}$ and dulaglutide $0.75 \mathrm{mg}$ in Chinese patients with T2D was evaluated. The incidence, severity, treatment discontinuation, duration, and time of occurrence of GI adverse events was evaluated up to week 26 , the primary endpoint for both the AWARD-CHN studies.
Post hoc analyses were conducted on the Chinese population based on the as-treated analysis set (safety analysis set). Safety analyses were conducted on patients who received at least one dose of dulaglutide $1.5 \mathrm{mg}$ or $0.75 \mathrm{mg}$ in both AWARD-CHN studies and were analyzed according to the treatment they actually received, regardless of their planned treatment. Descriptive statistics were used to present the data in this post hoc analysis, which included counts and percentages for categorical variables; counts, median, and minimum and maximum for continuous variables.

Adverse events were defined as TEAEs if events were newly reported or reported to worsen in severity after the initiation of study drug treatment. TEAE grading was performed by local site investigators and reported through the electronic case report form. Adverse events were classified according to the Medical Dictionary for Regulatory Activities (MedDRA) version 19.1 and summarized by treatment arm. Adverse events were categorized as mild, moderate, and severe. The duration of an adverse event was calculated as the adverse event end date minus the adverse event start date plus 1 day and was reported in terms of median number of days. Time-to-onset of an adverse event was analyzed by day, from the first dose date of the study drug to the occurrence of the adverse event.

\section{RESULTS}

\section{Patient Disposition and Baseline Characteristics}

A total of 787 Chinese patients with T2D were included in this post hoc analysis. Patients' baseline characteristics were similar between dulaglutide $1.5 \mathrm{mg}$ and $0.75 \mathrm{mg}$ groups. The majority of patients were male (59\%). Mean body weight was $70.7 \mathrm{~kg}$ in patients treated with dulaglutide $1.5 \mathrm{mg}$ and $72.0 \mathrm{~kg}$ in patients treated with dulaglutide $0.75 \mathrm{mg}$. Mean BMI was $25.7 \mathrm{~kg} / \mathrm{m}^{2}$ and $26.1 \mathrm{~kg} / \mathrm{m}^{2}$ in the dulaglutide $1.5 \mathrm{mg}$ and $0.75 \mathrm{mg}$ groups, respectively (Table 1). 
Table 1 Patient characteristics

\begin{tabular}{|c|c|c|c|}
\hline & $\begin{array}{l}\mathrm{DU} \\
1.5 \mathrm{mg} \\
N=392\end{array}$ & $\begin{array}{l}\mathrm{DU} \\
0.75 \mathrm{mg} \\
N=395\end{array}$ & $\begin{array}{l}\text { All DU } \\
N=787\end{array}$ \\
\hline \multicolumn{4}{|l|}{ Sex } \\
\hline Male, $n(\%)$ & $\begin{array}{l}230 \\
\quad(58.7)\end{array}$ & $\begin{array}{l}234 \\
\quad(59.2)\end{array}$ & $\begin{array}{l}464 \\
(59.0)\end{array}$ \\
\hline Female, $n(\%)$ & $\begin{array}{l}162 \\
(41.3)\end{array}$ & $\begin{array}{l}161 \\
\quad(40.8)\end{array}$ & $\begin{array}{l}323 \\
(41.0)\end{array}$ \\
\hline Age (years) & $\begin{array}{l}53.8 \\
\quad(10.2)\end{array}$ & $\begin{array}{l}54.0 \\
(9.9)\end{array}$ & $\begin{array}{l}53.9 \\
(10.0)\end{array}$ \\
\hline Body weight (kg) & $\begin{array}{l}70.7 \\
\quad(11.6)\end{array}$ & $\begin{array}{l}72.0 \\
(12.1)\end{array}$ & $\begin{array}{l}71.4 \\
\quad(11.9)\end{array}$ \\
\hline BMI $\left(\mathrm{kg} / \mathrm{m}^{2}\right)^{\mathrm{a}}$ & $\begin{array}{l}25.7 \\
(3.2)\end{array}$ & $\begin{array}{l}26.1 \\
(3.3)\end{array}$ & $\begin{array}{l}25.9 \\
(3.3)\end{array}$ \\
\hline $\begin{array}{l}\text { Duration of T2D } \\
\text { (years) }\end{array}$ & $5.9(5.0)$ & $5.6(5.4)$ & $5.8(5.2)$ \\
\hline HbAlc (\%) & $8.2(1.1)$ & $8.2(1.0)$ & $8.2(1.1)$ \\
\hline $\begin{array}{l}\text { Fasting blood glucose } \\
\qquad(\mathrm{mmol} / \mathrm{L})^{\mathrm{b}}\end{array}$ & $9.5(2.6)$ & $9.5(2.4)$ & $9.5(2.5)$ \\
\hline
\end{tabular}

Values shown are for mean (SD) unless otherwise noted $H b A 1 c$ glycated hemoglobin, BMI body mass index, $D U$ dulaglutide, $N$ total number of patients in specified treatment arm, $n$ number of patients in the specified category in specified treatment arm, $S D$ standard deviation, $T 2 D$ type 2 diabetes

a DU $1.5 \mathrm{mg}, N=392$; DU $0.75 \mathrm{mg}, N=394$; All DU, $N=786$

b DU $1.5 \mathrm{mg}, N=391$; DU $0.75 \mathrm{mg}, N=393$; All DU, $N=784$

\section{Incidence of Gastrointestinal Adverse Events}

Through week 26, 225 of the 787 patients $(28.6 \%)$ in the safety analysis set experienced at least one GI TEAE [dulaglutide $1.5 \mathrm{mg}$ group: 134 patients (34.2\%); dulaglutide $0.75 \mathrm{mg}$ group: 91 patients (23.0\%)]. The most frequently reported GI TEAEs in all dulaglutidetreated patients included diarrhea (13.1\%),
Table 2 Incidence of gastrointestinal treatment-emergent adverse events

\begin{tabular}{|c|c|c|c|}
\hline & $\begin{array}{l}\mathrm{DU} \\
1.5 \mathrm{mg} \\
N=392\end{array}$ & $\begin{array}{l}\mathrm{DU} \\
0.75 \mathrm{mg} \\
N=395\end{array}$ & $\begin{array}{l}\text { All DU } \\
N=787\end{array}$ \\
\hline $\begin{array}{l}\text { Patients with } \geq 1 \\
\text { GI TEAE, } n(\%)\end{array}$ & $134(34.2)$ & $91(23.0)$ & $225(28.6)$ \\
\hline Diarrhea & $66(16.8)$ & $37(9.4)$ & $103(13.1)$ \\
\hline Nausea & $38(9.7)$ & $14(3.5)$ & $52(6.6)$ \\
\hline $\begin{array}{l}\text { Abdominal } \\
\text { distension }\end{array}$ & $33(8.4)$ & $17(4.3)$ & $50(6.4)$ \\
\hline Vomiting & $22(5.6)$ & $2(0.5)$ & $24(3.0)$ \\
\hline Constipation & $14(3.6)$ & $8(2.0)$ & $22(2.8)$ \\
\hline $\begin{array}{l}\text { Abdominal pain } \\
\text { upper }\end{array}$ & $9(2.3)$ & $6(1.5)$ & $15(1.9)$ \\
\hline $\begin{array}{l}\text { Abdominal } \\
\text { discomfort }\end{array}$ & $7(1.8)$ & $4(1.0)$ & $11(1.4)$ \\
\hline Abdominal pain & $4(1.0)$ & $4(1.0)$ & $8(1.0)$ \\
\hline Eructation & $6(1.5)$ & $2(0.5)$ & $8(1.0)$ \\
\hline Toothache & $2(0.5)$ & $5(1.3)$ & $7(0.9)$ \\
\hline $\begin{array}{l}\text { Epigastric } \\
\text { discomfort }\end{array}$ & $4(1.0)$ & $2(0.5)$ & $6(0.8)$ \\
\hline
\end{tabular}

The denominator for all percentages is the number of patients in the specified treatment arm

$D U$ dulaglutide, $G I$ gastrointestinal, $N$ total number of patients in specified treatment arm, $n$ number of patients in the specified category in specified treatment arm, TEAE treatment-emergent adverse event

nausea (6.6\%), abdominal distension (6.4\%), and vomiting (3.0\%) (Table 2).

The incidence of GI TEAEs by their severity is shown in Table 3. The majority of the TEAEs were mild to moderate in severity, with $19.6 \%$ of patients experiencing mild TEAEs, $5.7 \%$ moderate TEAEs, and $0.4 \%$ severe TEAEs. The severity of diarrhea, nausea, abdominal distension, and vomiting was mostly mild to moderate, in proportions of $92 \%$ (95/103 patients), $88 \%$ ( $46 / 52$ patients), 94\% (47/50 patients), and $83 \%$ (20/24 patients), respectively. 
Table 3 Summary of severity of gastrointestinal treatment-emergent adverse events

\begin{tabular}{|c|c|c|c|}
\hline & $\begin{array}{l}\mathrm{DU} \\
1.5 \mathrm{mg} \\
N=392\end{array}$ & $\begin{array}{l}\mathrm{DU} \\
0.75 \mathrm{mg} \\
N=395\end{array}$ & $\begin{array}{l}\text { All DU } \\
N=787\end{array}$ \\
\hline $\begin{array}{l}\text { Patients with } \geq 1 \\
\text { GI TEAE, } n(\%)\end{array}$ & $134(34.2)$ & $91(23.0)$ & $225(28.6)$ \\
\hline Mild & $90(23.0)$ & $64(16.2)$ & $154(19.6)$ \\
\hline Moderate & $29(7.4)$ & $16(4.1)$ & $45(5.7)$ \\
\hline Severe & $3(0.8)$ & $0(0.0)$ & $3(0.4)$ \\
\hline Diarrhea, $n(\%)$ & $66(16.8)$ & $37(9.4)$ & $103(13.1)$ \\
\hline Mild & $45(11.5)$ & $28(7.1)$ & $73(9.3)$ \\
\hline Moderate & $16(4.1)$ & $6(1.5)$ & $22(2.8)$ \\
\hline Severe & $1(0.3)$ & $0(0.0)$ & $1(0.1)$ \\
\hline Nausea, $n(\%)$ & $38(9.7)$ & $14(3.5)$ & $52(6.6)$ \\
\hline Mild & $28(7.1)$ & $10(2.5)$ & $38(4.8)$ \\
\hline Moderate & $7(1.8)$ & $1(0.3)$ & $8(1.0)$ \\
\hline Severe & $2(0.5)$ & $0(0.0)$ & $2(0.3)$ \\
\hline $\begin{array}{l}\text { Abdominal } \\
\text { distension, } n(\%)\end{array}$ & $33(8.4)$ & $17(4.3)$ & $50(6.4)$ \\
\hline Mild & $28(7.1)$ & $15(3.8)$ & $43(5.5)$ \\
\hline Moderate & $2(0.5)$ & $2(0.5)$ & $4(0.5)$ \\
\hline Severe & $0(0.0)$ & $0(0.0)$ & $0(0.0)$ \\
\hline Vomiting, $n(\%)$ & $22(5.6)$ & $2(0.5)$ & $24(3.0)$ \\
\hline Mild & $13(3.3)$ & $1(0.3)$ & $14(1.8)$ \\
\hline Moderate & $5(1.3)$ & $1(0.3)$ & $6(0.8)$ \\
\hline Severe & $2(0.5)$ & $0(0.0)$ & $2(0.3)$ \\
\hline
\end{tabular}

Table shows the GI TEAEs reported in at least 5\% of patients in any treatment group. The denominator for all the percentages is the number of patients in the specified treatment arm

$D U$ dulaglutide, $G I$ gastrointestinal, $N$ total number of patients in specified treatment arm, $n$ number of patients in the specified category in specified treatment arm, TEAE treatment-emergent adverse event
Table 4 Summary of gastrointestinal treatment-emergent adverse events leading to treatment discontinuation

\begin{tabular}{llll}
\hline & $\begin{array}{l}\text { DU } \\
\mathbf{1 . 5} \mathbf{~ m g} \\
\boldsymbol{N}=\mathbf{3 9 2}\end{array}$ & $\begin{array}{l}\text { DU } \\
\mathbf{0 . 7 5} \mathbf{~ m g}\end{array}$ & $\begin{array}{l}\text { All DU } \\
\boldsymbol{N}=\mathbf{3 9 5}\end{array}$ \\
\hline $\begin{array}{llll}\text { Patients with } \geq 1 \mathrm{GI} \\
\text { TEAE, } n \text { (\%) }\end{array}$ & $8(2.0)$ & $4(1.0)$ & $12(1.5)$ \\
Diarrhea & $4(1.0)$ & $2(0.5)$ & $6(0.8)$ \\
Abdominal discomfort & $0(0.0)$ & $1(0.3)$ & $1(0.1)$ \\
Chronic gastritis & $1(0.3)$ & $0(0.0)$ & $1(0.1)$ \\
Duodenal ulcer & $0(0.0)$ & $1(0.3)$ & $1(0.1)$ \\
GI disorder & $1(0.3)$ & $0(0.0)$ & $1(0.1)$ \\
Impaired gastric & $1(0.3)$ & $0(0.0)$ & $1(0.1)$ \\
emptying & & & $1(0.1)$ \\
\hline Vomiting & $1(0.3)$ & $0(0.0)$ & \\
\hline
\end{tabular}

$D U$ dulaglutide, $G I$ gastrointestinal, $N$ total number of patients in specified treatment arm, $n$ number of patients in the specified category in specified treatment arm, TEAE treatment-emergent adverse event

\section{Gastrointestinal Adverse Events Leading to Treatment Discontinuation}

Only 12 patients (1.5\%) discontinued treatment as a result of GI TEAEs [dulaglutide $1.5 \mathrm{mg}$ group: $n=8(2.0 \%)$; dulaglutide $0.75 \mathrm{mg}$ group: $n=4(1.0 \%)]$. Diarrhea $(n=6 ; 0.8 \%)$ was the leading cause of study treatment discontinuation in both groups. The other TEAEs that led to treatment discontinuation are reported in Table 4.

Duration of First Reported

Gastrointestinal Treatment-Emergent Adverse Events and Most Commonly Reported Gastrointestinal TreatmentEmergent Adverse Events Through Week 26

The durations of the most common first reported GI TEAEs through week 26 are shown in Table 5 . The median duration of first reported GI TEAEs of diarrhea, nausea, abdominal 
Table 5 Summary of duration of first reported gastrointestinal treatment-emergent adverse events and most commonly reported gastrointestinal treatment-emergent adverse events up to week 26

\begin{tabular}{|c|c|c|c|c|c|}
\hline & \multirow[t]{2}{*}{$N$} & \multicolumn{2}{|c|}{ First reported GI TEAEs } & \multicolumn{2}{|c|}{ Most commonly reported GI TEAEs up to week 26} \\
\hline & & $\begin{array}{l}\text { Number of patients } \\
n(\%)\end{array}$ & $\begin{array}{l}\text { Duration (day) } \\
\text { Median (Q1, Q3) }\end{array}$ & Number of events & $\begin{array}{l}\text { Duration (day) } \\
\text { Median (Q1, Q3) }\end{array}$ \\
\hline \multicolumn{6}{|l|}{ Diarrhea } \\
\hline DU $1.5 \mathrm{mg}$ & 392 & $51(13.0)$ & $5.0(3,8)$ & 112 & $3.0(2,6)$ \\
\hline DU $0.75 \mathrm{mg}$ & 395 & $32(8.1)$ & $4.0(2,11)$ & 57 & $2.0(2,6.5)$ \\
\hline All DU & 787 & $83(10.5)$ & $4.0(2,8)$ & 169 & $3.0(2,6)$ \\
\hline \multicolumn{6}{|l|}{ Nausea } \\
\hline DU $1.5 \mathrm{mg}$ & 392 & $32(8.2)$ & $6.0(3,14)$ & 56 & $3.0(2,8)$ \\
\hline DU $0.75 \mathrm{mg}$ & 395 & $14(3.5)$ & $2.5(1,12)$ & 15 & $2.0(1,12)$ \\
\hline All DU & 787 & $46(5.8)$ & $5.0(2,12)$ & 71 & $3.0(2,8)$ \\
\hline \multicolumn{6}{|c|}{ Abdominal distension } \\
\hline DU $1.5 \mathrm{mg}$ & 392 & $28(7.1)$ & $11.0(4,43)$ & 48 & $4.0(2,14)$ \\
\hline DU $0.75 \mathrm{mg}$ & 395 & $16(4.1)$ & $18.5(5,45)$ & 18 & $18.0(5,45)$ \\
\hline All DU & 787 & $44(5.6)$ & $12.5(4.5,44)$ & 66 & $6.5(2,20.5)$ \\
\hline \multicolumn{6}{|l|}{ Vomiting } \\
\hline DU $1.5 \mathrm{mg}$ & 392 & $18(4.6)$ & $4.0(3,8)$ & 24 & $4.5(2,8)$ \\
\hline DU $0.75 \mathrm{mg}$ & 395 & $1(0.3)$ & $1.0(1,1)$ & 2 & $1.0(1,1)$ \\
\hline All DU & 787 & $19(2.4)$ & $4.0(2,8)$ & 26 & $4.0(2,8)$ \\
\hline
\end{tabular}

Table shows the top four among the first reported GI TEAEs of DU $1.5 \mathrm{mg}$ and $0.75 \mathrm{mg}$ treatment group and incidence of GI TEAEs through week 26

$D U$ dulaglutide, $G I$ gastrointestinal, $N$ total number of patients in specified treatment arm, $n$ number of patients in the specified category in specified treatment arm, Q1 25th percentile, Q3 75th percentile, TEAE treatment-emergent adverse event

distension, and vomiting was 4.0, 5.0, 12.5, and 4.0 days, respectively, in all dulaglutide-treated patients. During the 26 weeks leading up to primary endpoint, the total number of events of diarrhea, nausea, abdominal distension, and vomiting in all dulaglutide-treated patients was $169,71,66$, and 26 , respectively. The median durations of these events were 3.0, 3.0, 6.5, and 4.0 days, respectively.

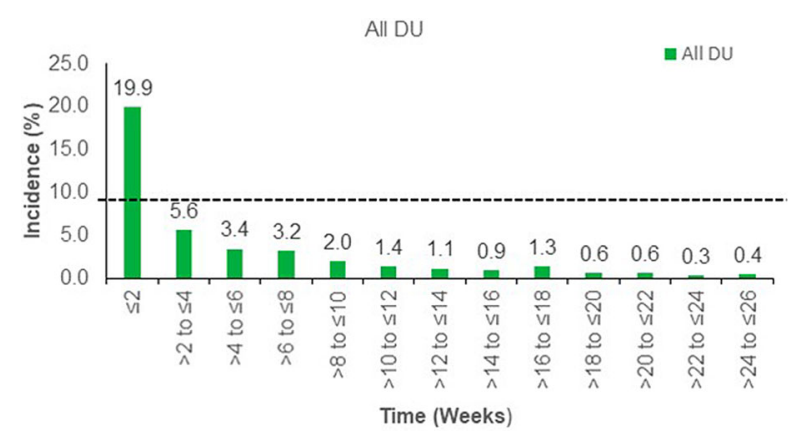

Fig. 1 Summary of time of occurrence of gastrointestinal treatment-emergent adverse events. $N=787$ for all DU. $D U$ dulaglutide, $N$ total number of patients 


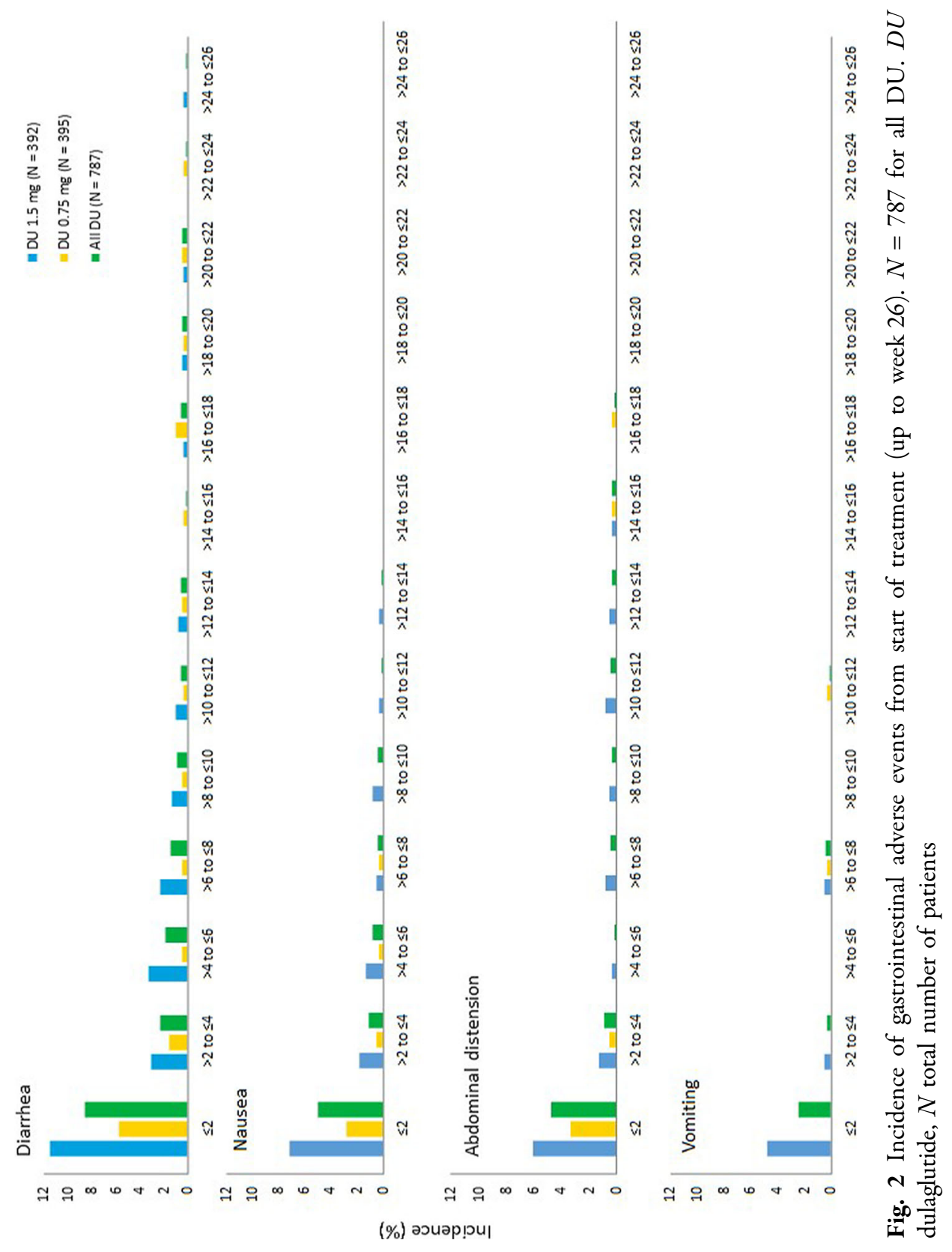




\section{Time of Occurrence of Gastrointestinal Treatment-Emergent Adverse Events}

Figure 1 shows all GI TEAEs reported in the combined dulaglutide treatment group. The incidence of GI TEAEs was more frequent during the first 2 weeks of dulaglutide treatment; the incidence of these TEAEs declined rapidly after 2 weeks and remained low until week 26 . The incidences of most commonly reported GI adverse events from baseline to week 26 , by 2-week intervals in each treatment group, are shown in Fig. 2 and follow the pattern of higher levels in the initial 2 weeks of dulaglutide treatment, decreasing rapidly after week 2 .

\section{DISCUSSION}

GI complaints are commonly reported by patients with diabetes, with some studies indicating that approximately $75 \%$ of patients with diabetes complain of having at least one GI symptom [25]. In patients with diabetes, inadequate glycemic control affects gastric motility and gastric emptying, which can lead to GI symptoms [22, 25].

The current post hoc pooled analysis assessed detailed and comprehensive GI adverse event data in a Chinese patient population. We investigated GI disorders including diarrhea, nausea, and vomiting, which are most commonly observed with GLP-1 RAs [22]. The AWARD studies have reported the overall safety data associated with dulaglutide in global and Asian patient populations [10-19]. Here, we report the GI safety profile with detailed GI adverse event data in Chinese patients from two phase III multicenter trials, pooled to assess GI data at week 26 [20, 21]. At week 26, 225 patients $(28.6 \%)$ reported at least one GI TEAE. The overall incidences of the most frequently reported GI TEAEs diarrhea, nausea, abdominal distension, and vomiting were $13.1 \%, 6.6 \%$, $6.4 \%$, and $3.0 \%$, respectively, and most GI TEAEs were mild to moderate in severity. Compared with the results of global phase III trials in global populations treated with dulaglutide, the overall incidences of diarrhea, nausea, abdominal distension, and vomiting were comparable or lower in this analysis $[9,26]$. A previously conducted pooled analysis reported that GI adverse events with onceweekly exenatide appeared to have no striking differences among different subpopulations of white, black, Asian, and Hispanic patients [27]. Also, a study that analyzed GI adverse event effects between GLP-1 RAs reported inconsistency in outcomes based on race/ethnicity [28]. Furthermore, previous studies with GLP-1 RAs reported that GI adverse events occurred more frequently in lower versus higher baseline BMI subgroups, although the exact cause for the observation has not been extensively studied [23]. However, these studies were conducted in a global population with a higher proportion of Caucasian patients. This analysis in Chinese patients found that even with a lower BMI, the GI adverse events are comparable with or lower than those observed in a global population treated with dulaglutide (1.5 $\mathrm{mg}$ and $0.75 \mathrm{mg}$ ) as reported in the AWARD studies [10-19]. Furthermore, when compared with the results in the Asian patient population across phase III clinical trials with other GLP-1 RAs, the incidence rates of GI adverse events were consistent with this analysis [29-32].

In this analysis, diarrhea was the most frequently occurring TEAE and demonstrated higher incidence when compared between Asian and non-Asian patient populations [9-21]. This finding is consistent with recent class-wide meta-analyses which report that, of the commonly experienced GI adverse events, nausea and vomiting are less common in longer-acting GLP-1 RAs like dulaglutide, but diarrhea may be more common [33]. The potential cause of diarrhea could be due to acceleration of colonic transit with a GLP-1 agonist, ROSE-010; also, the GLP-1 agonists may have effects on the TGBAR receptor or other mechanisms that impact physiological secretion of bile acids [34]. The effects of GLP-1 RAs on gut other than stomach have not been extensively studied; however, the potential of GLP-1 RAs to inhibit small intestine motor function has been reported, which may contribute to lower GI symptoms such as diarrhea and constipation [28, 35]. Although incidence of diarrhea reported in this analysis was higher 
when compared with a non-Asian patient population $[9,12]$, it was comparable to that in a Japanese patient population treated with onceweekly dulaglutide $0.75 \mathrm{mg}$ [36], indicating no major difference in GI-related safety parameters between Chinese and Japanese patient populations.

The incidence of GI TEAEs was observed to be higher with dulaglutide $1.5 \mathrm{mg}$ compared with dulaglutide $0.75 \mathrm{mg}$, but this was expected because of the higher dosage. Of note, the GI TEAEs reported in this analysis were transient in nature and mild to moderate in severity, with very few patients discontinuing treatment as a result of GI TEAEs. Also, the mean duration of first reported diarrhea, nausea, and vomiting was relatively short ( $\leq 5$ days), and incidence of GI TEAEs was more pronounced during the first 2 weeks of dulaglutide treatment but declined rapidly as treatment continued, and was low at week 26.

There are some limitations of this analysis. As a post hoc analysis, the results need to be analyzed and interpreted with caution. Also, patients enrolled in the individual clinical trials were controlled by study-specific inclusion and exclusion criteria that may vary from the general population. To overcome these limitations, real-world studies that assess long-term effectiveness and safety of GLP-1 RAs are needed.

\section{CONCLUSIONS}

The present post hoc pooled analysis of two studies revealed that the overall incidences of GI TEAEs were most pronounced during the first 2 weeks of dulaglutide treatment but declined rapidly as treatment continued. These incidences were low at week 26 , indicating that dulaglutide is well tolerated in Chinese patients with T2D. The findings from this analysis are consistent with the data from global, Japanese, and other Asian patient populations with T2D.

\section{ACKNOWLEDGEMENTS}

Funding. This study and the journal's Rapid Service Fee were funded by Eli Lilly and Company.

Medical Writing Assistance. The authors would like to thank Dr. Rakesh Ojha, PhD and Deepika Kajarekar, both of Syneos Health, for medical writing support in the preparation of this manuscript. Support for this assistance was funded by Eli Lilly and Company.

Authorship. All named authors meet the International Committee of Medical Journal Editors (ICMJE) criteria for authorship for this article, take responsibility for the integrity of the work as a whole, and have given their approval for this version to be published.

Authorship Contributions. Bin Zhang was involved in conception, analysis of data, and interpretation of data. Jianing Zhou was involved in conception, design, and interpretation of data. Lixin Guo was involved in analysis of data and interpretation of data. Zhiguang Zhou was involved in acquisition of data and interpretation of data.

Prior Presentation. The contents of this manuscript were previously presented as a poster at The 22nd Scientific Meeting of the Chinese Diabetes Society; Suzhou, China; Nov 28-Dec 1, 2018.

Disclosures. Bin Zhang and Jianing Hou are employees of Eli Lilly and Company. Lixin Guo and Zhiguang Zhou have nothing to disclose.

Compliance with Ethics Guidelines. Institutional ethics committee approval was obtained for both studies, and written informed consent was taken from each patient before participation. Both studies were conducted in accordance with the Declaration of Helsinki, Good Clinical Practice, and applicable laws and regulations (World Medical Association Declaration of Helsinki, 1997) [24]. 
Data Availability. The datasets generated during and/or analyzed during the current study are available from the corresponding author on reasonable request.

Open Access. This article is licensed under a Creative Commons Attribution-NonCommercial 4.0 International License, which permits any non-commercial use, sharing, adaptation, distribution and reproduction in any medium or format, as long as you give appropriate credit to the original author(s) and the source, provide a link to the Creative Commons licence, and indicate if changes were made. The images or other third party material in this article are included in the article's Creative Commons licence, unless indicated otherwise in a credit line to the material. If material is not included in the article's Creative Commons licence and your intended use is not permitted by statutory regulation or exceeds the permitted use, you will need to obtain permission directly from the copyright holder. To view a copy of this licence, visit http://creativecommons.org/licenses/by$\mathrm{nc} / 4.0 /$.

\section{REFERENCES}

1. Cho NH, Shaw JE, Karuranga S, et al. IDF Diabetes Atlas: global estimates of diabetes prevalence for 2017 and projections for 2045. Diabetes Res Clin Pract. 2018;138:271-81.

2. $\mathrm{Hu} \mathrm{C}, \mathrm{Jia} \mathrm{W}$. Diabetes in China: epidemiology and genetic risk factors and their clinical utility in personalized medication. Diabetes. 2018;67:3-11.

3. Marín-Peñalver JJ, Martín-Timón I, Sevillano-Collantes C, Del Cañizo-Gómez FJ. Update on the treatment of type 2 diabetes mellitus. World J Diabetes. 2016;7:354-95.

4. American Diabetes Association. Pharmacologic approaches to glycemic treatment: standards of medical care in diabetes-2020. Diabetes Care. 2020;43(Suppl 1):S98-S110. https://doi.org/10. 2337/dc20-S009.

5. American Diabetes Association. Cardiovascular disease and risk management: standards of medical care in diabetes-2020. Diabetes Care. 2020;Suppl 1:S103-S123123. https://doi.org/10.2337/dc19S010.
6. Jia W, Weng J, Zhu D, et al. Standards of medical care for type 2 diabetes in China 2019. Diabetes Metab Res Rev. 2019;35:e3158.

7. Saisho Y. $\beta$-Cell dysfunction: its critical role in prevention and management of type 2 diabetes. World J Diabetes. 2015;6:109-24.

8. Meloni AR, DeYoung MB, Lowe C, Parkes DG. GLP1 receptor activated insulin secretion from pancreatic $\beta$-cells: mechanism and glucose dependence. Diabetes Obes Metab. 2013;15:15-27.

9. Grunberger G, Chang A, Garcia Soria G, Botros FT, Bsharat R, Milicevic Z. Monotherapy with the onceweekly GLP-1 analogue dulaglutide for 12 weeks in patients with type 2 diabetes: dose-dependent effects on glycaemic control in a randomized, double-blind, placebo-controlled study. Diabet Med. 2012;29:1260-7.

10. Wysham C, Blevins T, Arakaki R, et al. Efficacy and safety of dulaglutide added onto pioglitazone and metformin versus exenatide in type 2 diabetes in a randomized controlled trial (AWARD-1). Diabetes Care. 2014;37:2159-67.

11. Giorgino F, Benroubi M, Sun JH, Zimmermann AG, Pechtner V. Efficacy and safety of once-weekly dulaglutide versus insulin glargine in patients with type 2 diabetes on metformin and glimepiride (AWARD-2). Diabetes Care. 2015;38:2241-9.

12. Umpierrez G, Tofé Povedano S, Pérez Manghi F, Shurzinske L, Pechtner V. Efficacy and safety of dulaglutide monotherapy versus metformin in type 2 diabetes in a randomized controlled trial (AWARD-3). Diabetes Care. 2014;37:2168-76.

13. Blonde L, Jendle J, Gross J, et al. Once-weekly dulaglutide versus bedtime insulin glargine, both in combination with prandial insulin lispro, in patients with type 2 diabetes (AWARD-4): a randomised, open-label, phase 3, non-inferiority study. Lancet. 2015;385:2057-66.

14. Nauck M, Weinstock RS, Umpierrez GE, Guerci B, Skrivanek Z, Milicevic Z. Efficacy and safety of dulaglutide versus sitagliptin after 52 weeks in type 2 diabetes in a randomized controlled trial (AWARD-5). Diabetes Care. 2014;37(8):2149-58.

15. Dungan KM, Povedano ST, Forst T, et al. Onceweekly dulaglutide versus once-daily liraglutide in metformin-treated patients with type 2 diabetes (AWARD-6): a randomised, open-label, phase 3, non-inferiority trial. Lancet. 2014;384:1349-57.

16. Tuttle KR, Lakshmanan MC, Rayner B, et al. Dulaglutide versus insulin glargine in patients with type 2 diabetes and moderate-to-severe chronic kidney disease (AWARD-7): a multicentre, open- 
label, randomised trial. Lancet Diabetes Endocrinol. 2018;6:605-17.

17. Dungan KM, Weitgasser R, Perez Manghi F, et al. A 24-week study to evaluate the efficacy and safety of once-weekly dulaglutide added on to glimepiride in type 2 diabetes (AWARD-8). Diabetes Obes Metab. 2016;18:475-82.

18. Pozzilli P, Norwood P, Jódar E, et al. Placebo-controlled, randomized trial of the addition of onceweekly glucagon-like peptide-1 receptor agonist dulaglutide to titrated daily insulin glargine in patients with type 2 diabetes (AWARD-9). Diabetes Obes Metab. 2017;19:1024-31.

19. Ludvik B, Frías JP, Tinahones FJ, et al. Dulaglutide as add-on therapy to SGLT2 inhibitors in patients with inadequately controlled type 2 diabetes (AWARD-10): a 24-week, randomised, double-blind, placebo-controlled trial. Lancet Diabetes Endocrinol. 2018;6:370-81.

20. Shi LX, Liu XM, Shi YQ, et al. Efficacy and safety of dulaglutide monotherapy compared with glimepiride in Chinese patients with type 2 diabetes: post-hoc analyses of a randomized, double-blind, phase III study. J Diabetes Investig. 2020;11:142-50.

21. Li Y, Li L, De Peng Y, et al. Efficacy and safety of dulaglutide versus insulin glargine in Chinese T2DM patients: a subgroup analysis of a randomized trial (AWARD-CHN2). Diabetes Ther. 2019;10: 1435-52.

22. Bettge K, Kahle M, Abd El Aziz MS, Meier JJ, Nauck M. Occurrence of nausea, vomiting and diarrhoea reported as adverse events in clinical trials studying glucagon-like peptide-1 receptor agonists: a systematic analysis of published clinical trials. Diabetes Obes Metab. 2017;19:336-47.

23. Ahrén B, Atkin SL, Charpentier G, et al. Semaglutide induces weight loss in subjects with type diabetes regardless of baseline BMI or gastrointestinal adverse events in the SUSTAIN 1 to 5 trials. Diabetes Obes Metab. 2018;20:2210-9.

24. World Medical Association Declaration of Helsinki. Recommendations guiding physicians in biomedical research involving human subjects. JAMA. 1997;277:925-6.

25. Krishnasamy S, Abell TL. Diabetic gastroparesis: principles and current trends in management. Diabetes Ther. 2018;9(Suppl 1):1-42.

26. Umpierrez GE, Blevins T, Rosenstock J, et al. The effects of LY2189265, a long-acting glucagon-like peptide- 1 analogue, in a randomized, placebo-controlled, double-blind study of overweight/obese patients with type 2 diabetes: the EGO study. Diabetes Obes Metab. 2011;13:418-25.

27. Pencek R, Blickensderfer A, Li Y, Brunell SC, Chen S. Exenatide once weekly for the treatment of type 2 diabetes: effectiveness and tolerability in patient subpopulations. Int J Clin Pract. 2012;66:1021-32.

28. Horowitz M, Aroda VR, Han J, Hardy E, Rayner CK. Upper and/or lower gastrointestinal adverse events with glucagon-like peptide-1 receptor agonists: incidence and consequences. Diabetes Obes Metab. 2017;19:672-81.

29. Chen YH, Huang CN, Cho YM, et al. Efficacy and safety of dulaglutide monotherapy compared with glimepiride in East-Asian patients with type 2 diabetes in a multicentre, double-blind, randomized, parallel-arm, active comparator, phase III trial. Diabetes Obes Metab. 2018;20:2121-30.

30. Wang W, Nevárez L, Filippova E, et al. Efficacy and safety of once-weekly dulaglutide versus insulin glargine in mainly Asian patients with type 2 diabetes mellitus on metformin and/or a sulphonylurea: a 52-week open-label, randomized phase III trial. Diabetes Obes Metab. 2019;21:234-43.

31. Gao Y, Yoon KH, Chuang LM, et al. Efficacy and safety of exenatide in patients of Asian descent with type 2 diabetes inadequately controlled with metformin or metformin and a sulphonylurea. Diabetes Res Clin Pract. 2009;83:69-766.

32. Yang W, Chen L, Ji Q, et al. Liraglutide provides similar glycaemic control as glimepiride (both in combination with metformin) and reduces body weight and systolic blood pressure in Asian population with type 2 diabetes from China, South Korea and India: a 16-week, randomized, doubleblind, active control trial. Diabetes Obes Metab. 2011;13:81-8.

33. Kugler AJ, Thiman ML. Efficacy and safety profile of once-weekly dulaglutide in type 2 diabetes: a report on the emerging new data. Diabetes Metab Syndr Obes. 2018;11:187-97.

34. Sun F, Yu K, Yang Z, et al. Impact of GLP-1 receptor agonists on major gastrointestinal disorders for type 2 diabetes mellitus: a mixed treatment comparison meta-analysis. Exp Diabetes Res. 2012;2012: 230624. https://doi.org/10.1155/2012/230624.

35. Thazhath SS, Marathe CS, Wu T, et al. The glucagon-like peptide 1 receptor agonist exenatide inhibits small intestinal motility, flow, transit, and absorption of glucose in healthy subjects and patients with type 2 diabetes: a randomized controlled trial. Diabetes. 2016;65:269-75. 
36. Inoue $M$, Shiramoto M, Oura T, Nasu R, Nakano M, Takeuchi M. Effect of once-weekly dulaglutide on glucose levels in Japanese patients with type 2 diabetes: findings from a phase 4, randomized controlled trial. Diabetes Ther. 2019;10:1019-27. 